\title{
ASSESSING ONION THRIPS' BEHAVIOUR IN THE PRESENCE OF REPELLENT AND ATTRACTANT VOLATILE ODOURS
}

\author{
R.W.H.M. VAN TOL ${ }^{1}$, D.E. JAMES ${ }^{2}$, W.J. DE KOGEL ${ }^{1}$ \\ and D.A.J. TEULON ${ }^{2}$ \\ ${ }^{1}$ Plant Research International, Wageningen-UR, P.O. Box 16, \\ 6700 AA Wageningen, The Netherlands \\ ${ }^{2}$ Crop \& Food Research, Private Bag 4704, Christchurch, New Zealand \\ Corresponding author: rob.vantol@wur.nl
}

\begin{abstract}
The efficacy of four plant essential oils to repel onion thrips, Thrips tabaci (Lindeman), was compared in the presence of an attractive odour, ethyl iso-nicotinate in a pasture field. Four horizontal white sticky plates (directions: N, S, E, W) were placed adjacent to a central horizontal white plate $(\mathrm{C})$ sprayed with ethyl iso-nicotinate. The four surrounding plates were sprayed with essential oils (Origanum majorana, Ocimum gratissimum, Artemisia arborescens and Melaleuca alternifolia) or water (control). After 24 hours, fewer onion thrips were found on the plates with $O$. majorana or $O$. gratissimum (87 and $71 \%$ less, respectively) compared to the control. Relative thrips numbers on each plate were compared with similar (N, S, E, W and C) plates in the control treatment. For the O. majorana-attractant combination, thrips distribution on the plates $(\mathrm{N}: \mathrm{S}: \mathrm{E}: \mathrm{W}: \mathrm{C}=10: 0: 14: 21: 55)$ was significantly different from the control-attractant combination $(\mathrm{N}: \mathrm{S}: \mathrm{E}: \mathrm{W}: \mathrm{C}=9: 23: 3: 47: 18)$. There were lower thrips numbers on the south (23\% reduction) and west (26\% reduction) $O$. majorana-treated plates and higher numbers ( $37 \%$ increase) on the central attractant-treated plate indicating a shortdistance push-pull effect. Artemisia arborescens and M. alternifolia were not effective in any treatments.
\end{abstract}

\section{EVALUATION OF METHYL SALICYLATE AS AN ATTRACTANT FOR BENEFICIAL INSECTS}

\author{
P.W. SHAW and D.R. WALLIS \\ HortResearch, PO Box 220, Motueka, New Zealand \\ Corresponding author: pshaw@hortresearch.co.nz.
}

Green leaf volatiles are typically released by plants immediately after wounding or herbivore attack and can serve as signals to some natural enemies. Research overseas has shown that a synthetic herbivore-induced plant volatile (HIPV) methyl salicylate was attractive to a number of beneficial insects, including ladybirds, predatory bugs and small parasitic wasps. Field trapping for related insects was conducted in three apple blocks at sites near Motueka in the Nelson district, New Zealand. Key beneficial insects trapped included the generalist predators Stethorus sp., Sejanus albisignata and small parasitic wasps. Apart from Trichogramma spp., which showed a positive response to methyl salicylate, similar numbers of insects were recorded in traps baited with methyl salicylate and in untreated control traps and there appeared to be no evidence of increased attraction to this HIPV. 